\title{
Efficacy in anterior uveitis of two known steroids and topical tolmetin
}

\author{
J A DUNNE,' N JACOBS, ' A MORRISON,' AND D J GILBERT' \\ From the 'Manchester Royal Eye Hospital and 'Smith and Nephew Research Limited
}

SUMmaRY We have compared the anti-inflammatory efficacy of $5 \%$ tolmetin sodium dihydrate, $0.5 \%$ prednisolone disodium phosphate, and $0.1 \%$ betamethasone disodium phosphate in 71 consecutive patients presenting with acute endogenous non-granulomatous uveitis randomly assigned to one of these treatment groups. Inflammatory symptoms and signs were scored during the course of the 21-day trial period. There was no statistically significant difference in the effect on the signs or symptoms of the three drugs tested. $90 \%$ of the Betnesol (betamethasone sodium phosphate, benzalkonium chloride) treated group were clinically judged cured compared with $68 \%$ of the Predsol (prednisolone sodium phosphate, benzalkonium chloride) treated group, and $57 \%$ of the tolmetin treated group.

Endogenous anterior uveitis is an iridocyclitic inflammatory disease of unknown origin. The condition is frequently recurrent and self limiting but requires treatment with non-specific agents such as corticosteroid preparations to suppress the signs and symptoms of inflammation, and mydriatic/cycloplegic therapy to avoid complications associated with inflammatory events in the anterior chamber. In acute endogenous anterior uveitis good control of inflammation is usually achieved with topical corticosteroids. Periocular and/or systemic steroid therapy is rarely required.' The beneficial effects of topical corticosteroids in inflammatory eye disease have been fairly well established in recent years. Well controlled double-blind trials have confirmed their efficacy against either standard treatments or placebos in both postsurgical inflammation ${ }^{2-4}$ and anterior uveitis. ${ }^{5-8}$

The widespread use of topical corticosteroids is not without clinical problems, however, and these are generally well known. Probably the most significant side effect occurs in the so called steroid responder, where serious and potentially sight threatening increases in intraocular pressure may occur, ${ }^{911}$ and perhaps the most important contraindication is in ocular inflammation associated with an infectious agent, particularly where that agent is a virus."

Correspondence to Mr J A Dunne, Victoria Hospital, Whinney Heys Road, Blackpool, Lancs FY3 8NR.
There is increasing evidence that prostaglandins are important mediators of the inflammatory process in the eye as well as in other tissues. They have been clearly implicated in postsurgical inflammation and anterior uveitis and may be responsible for many of the clinical features observed in these conditions. ${ }^{12-14}$ With this realisation of the important role that prostaglandins play has come an interest in the use of non-steroidal anti-inflammatory agents as potential alternatives to the long established steroid therapy. One such non-steroidal anti-inflammatory drug that has had widespread usage as a systemic treatment for rheumatoid arthritis and allied conditions is tolmetin ${ }^{15}$ (Tolectin). This compound, which is a pyrrole acetic acid derivative without the indole nucleus present in indomethacin, is a potent inhibitor of prostaglandin synthetase ${ }^{16}$ and has been developed as an ophthalmic solution. Tolmetin is highly effective as a topical anti-inflammatory agent in an experimental model of immunogenic uveitis. ${ }^{17}$ Tolmetin ophthalmic solution has also been shown to be beneficial, when compared with saline, in a small group of patients treated after cataract surgery ( $\mathrm{R}$ Mapstone, personal communication).

The objective of this double-masked trial in patients with acute endogenous non-granulomatous anterior uveitis was to compare the anti-inflammatory efficacy of $5.0 \%$ tolmetin ophthalmic solution with two commonly prescribed steroidal preparations, Predsol $0 \cdot 5 \%$ and Betnesol $0 \cdot 1 \%$. 
Table 1 Assessments of symptoms and signs of inflammation made on days $1,3,7,14$, and 21 of the trial

\begin{tabular}{ll}
\hline Symptom & Score \\
\hline Photophobia & $0,1,2$, or 3 \\
Pain & $0,1,2$, or 3 \\
Blurring & $0,1,2$, or 3 \\
Watering & $0,1,2$, or 3 \\
Sign & \\
Corncal ocdema & 0,1, or 2 \\
Posterior synechia & 0,1, or 2 \\
Ciliary injection & $0,1,2$, or 3 \\
Keratic precipitates & $0,1,2$, or 3 \\
Aqueous flare & $0,1,2$, or 3 \\
Aqueous cells & $0,1,2$, or 3 \\
Vitreous cells & $0,1,2$, or 3 \\
Exudatc & 0 (absent) or 3 (present) \\
Hypopyon & 0 (absent) or 3 (prescnt) \\
Ptosis & 0 (absent) or 3 (prescnt) \\
Mobility of aqueous cells & 0 (mobilc) or 3 (stationary) \\
$\quad$ (if present) & \\
\hline
\end{tabular}

$0=$ Nonc. 1 = Mild. 2 = Moderate. 3 =Scvere.

\section{Materials and methods}

Patients and trial design. Seventy-one consecutive patients presenting at the Casualty Department of the Manchester Royal Eye Hospital with acute endogenous non-granulomatous anterior uveitis were included in the study. Patients on topical or systemic steroids for other conditions and pregnant women were excluded. The purpose of the trial was explained to each patient, and their verbal consent was obtained. One patient declined to take part in the study.

For each patient a clinical history was taken, and a record form was completed. Details of the patient's subjective assessment of the discomfort of the affected eye, a full detailed slit lamp biomicroscope examination, visual acuities, and intraocular pressure were recorded on the patient's record form. In addition all patients had chest and sacroiliac joint $x$-rays taken.

Patients were assigned consecutive trial numbers
(1-71) and thereby allocated to one of three treatment groups by the Pharmacy Department, which held the randomised treatment code. Neither patient nor ophthalmologist was advised of the nature of the treatment. The patients received either tolmetin sodium dihydrate $5.0 \%$ solution, prednisolone disodium phosphate $0.5 \%$ (Predsol), or betamethasone disodium phosphate $0 \cdot 1 \%$ (Betnesol). They were asked to instil one drop into the affected eye every two hours during the waking period of each day, and this treatment regimen was subsequently reduced by the examining ophthalmologist as required. Initially all patients also received atropine $1.0 \%$ once daily.

Assessments. On admission to the trial at the first visit (day 1) a detailed clinical history was taken and record admission forms completed. The patient's symptoms, clinical signs, and intraocular pressure were recorded on day 1 and then on days $3,7,14$, and 21 of treatment. The symptoms and signs weighted scoring procedure is shown in Table 1 . Side effects noted were recorded on days $3,7,14$, and 21 .

Statistical analysis. Much of the data collected were subjective scores, and consequently mainly nonparametric methods have been used for the statistical analyses. These were the Kruskal-Wallis analysis of variance (ANOVA) and the $\chi^{2}$ tests used to test comparability of treatment groups at the start of the trial and to make comparisons between treatment groups during treatment. The Wilcoxon signed rank test was used for comparisons within treatment groups. Within-group comparisons with baseline scores quote single tail probabilities. Between-group comparisons quote two tailed probabilities. $p<0.05$ is considered to be statistically significant.

\section{Results}

Patient comparability. Of the 71 patients included in the study on day 1, 11 have not been included in the statistical analyses. Four of the excluded patients did not return to the clinic for follow-up visits at an early stage in the trial. Another four did not reattend at all.

Table 2 Numbers of cases with mild or severe uveitis at presentation and associations with clinical history data

\begin{tabular}{|c|c|c|c|c|c|c|}
\hline \multirow{3}{*}{$\begin{array}{l}\text { Data from clinical history which show factors possibly associated with uveitis and } \\
\text { clinical outcome }\end{array}$} & \multicolumn{6}{|c|}{ Group } \\
\hline & \multicolumn{2}{|c|}{ Tolmetin } & \multicolumn{2}{|c|}{ Predsol } & \multicolumn{2}{|c|}{ Betnesol } \\
\hline & Mild & Severe & Mild & Severe & Mild & Severe \\
\hline Cases at initial assessment & 7 & 14 & 8 & 11 & 10 & 10 \\
\hline Cases with clinical or radiological cvidence of ankylosing spondylitis or sacroillitis & 2 & 4 & 3 & 3 & 4 & 3 \\
\hline Cases with recurrent or previous uveitis & 3 & 3 & 4 & 3 & 6 & 6 \\
\hline Cases with ankylosing spondylitis or sacroillitis and previous uvcitis & 1 & 0 & 2 & 1 & 4 & 2 \\
\hline
\end{tabular}


Table 3 Treatment group mean total scores for patient symptoms at initial visit and at days 3, 7, 14, and 21 during treatment. Statistical significance of within group score reductions assessed by Wilcoxon signed ranks test (one tailed)

\begin{tabular}{|c|c|c|c|c|c|c|c|c|c|}
\hline \multirow[t]{3}{*}{ Visit } & \multicolumn{9}{|c|}{ Treatment group (number of patients) } \\
\hline & \multicolumn{3}{|c|}{ Tolmetin (2I) } & \multicolumn{3}{|c|}{ Predsol (19) } & \multicolumn{3}{|c|}{ Betnesol (20) } \\
\hline & $\begin{array}{l}\text { Mean } \\
\text { score }\end{array}$ & $\begin{array}{l}\% \text { Initial } \\
\text { score }\end{array}$ & $p$ & $\begin{array}{l}\text { Mean } \\
\text { score }\end{array}$ & $\begin{array}{l}\% \text { Initial } \\
\text { score }\end{array}$ & $p$ & $\begin{array}{l}\text { Mean } \\
\text { score }\end{array}$ & $\begin{array}{l}\% \text { Initial } \\
\text { score }\end{array}$ & $p$ \\
\hline Initial & $5 \cdot 80$ & 100 & & $5 \cdot 16$ & 100 & & $4 \cdot 70$ & 100 & \\
\hline 3 Days & $4 \cdot 75$ & 82 & $<0 \cdot 05$ & $4 \cdot 42$ & 86 & $<0 \cdot(04$ & $2 \cdot 90$ & 62 & $<0 \cdot 003$ \\
\hline 7 Days & $3 \cdot 85$ & 66 & $<0 \cdot() 2$ & $3 \cdot 74$ & 72 & $<0 \cdot(005$ & $2 \cdot 85$ & 61 & $<0 \cdot 007$ \\
\hline 14 Days & $3 \cdot 80$ & 66 & $<0 \cdot(0) 6$ & $3 \cdot 21$ & 62 & $<0 .(0) 3$ & $2 \cdot 45$ & 52 & $<0.001$ \\
\hline 21 Days & $3 \cdot 85$ & 66 & $<0 \cdot 0007$ & $3 \cdot(0)$ & 58 & $<0 \cdot(0) 3$ & $2 \cdot 20$ & 47 & $<0.001$ \\
\hline
\end{tabular}

One patient in the Predsol group was inadvertently changed to treatment with Betnesol, and these results were excluded. Two patients in the Betnesol group developed bilateral uveitis and were removed from the study.

The remaining 60 patients were randomly assigned to groups treated with either topical tolmetin (21 patients), or Predsol (19 patients), or Betnesol (20 patients). Patient comparability assessed on the initial visit was good. There were no significant differences between the groups. The mean age was $40-45$ years (range 13-72 years), and the proportion of females to males (approximately 2:1) was similar in all groups. There were no significant differences in the number of previous attacks. Over one-third of the patients had had no previous attack of uveitis. The duration of present symptoms was also similar in all three groups. Approximately $40 \%$ of patients had had their present attack symptoms for more than three days and over $80 \%$ of patients for more than seven days.

Analysis of records of past medical and family history was carried out, but nothing was found to suggest that the randomised treatment allocation of patients to treatment groups resulted in dissimilar groups. The results are shown in Table 2.

Statistical analysis. During the course of the trial a number of patients were removed from the study because of lack of response to treatment. Where this occurred the last available signs and symptoms scores have been carried over into missing assessment periods until the end of the trial (21 days). This procedure introduces less bias into the analysis than some alternative procedures, such as our ignoring all results relating to such patients.

Symptom scores. The patients' symptoms were assessed by our questioning the patient according to the scoring scheme shown in Table 1 at the initial visit and subsequently at $3,7,14$, and 21 days.

The four symptom scores were summed for each patient and mean total symptom scores determined for each group. Statistically significant improvements in total symptom scores were seen in all three treatment groups at days $3,7,14$, and 21 . These data are shown in Table 3 and Fig. 1. Between-group comparisons showed no statistically significant difference
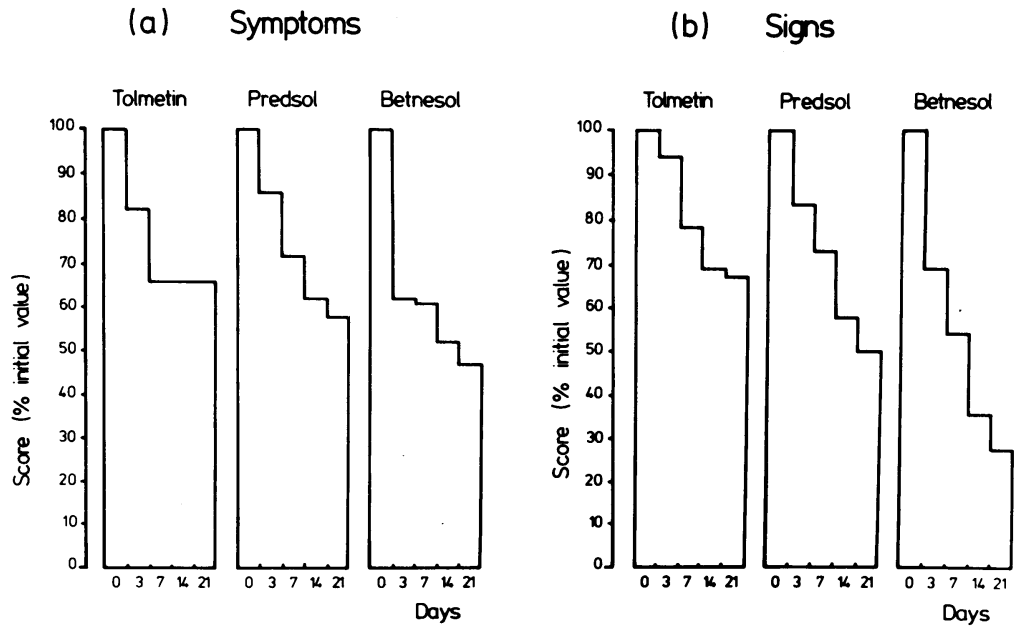

Fig. 1 Change in symptom and sign scores after treatment with tolmetin, predsol, or betnesol as a percentage of initial score. 
Table 4 Treatment group mean total scores for patient signs of inflammation at initial visit and at days 3, 7, 14, and 21 during treatment. Statistical significance of within group score reductions assessed by Wilcoxon signed rank test (one tailed)

\begin{tabular}{|c|c|c|c|c|c|c|c|c|c|}
\hline \multirow[t]{3}{*}{ Visit } & \multicolumn{9}{|c|}{ Treatment group (number of patients) } \\
\hline & \multicolumn{3}{|c|}{ Tolmetin (2I) } & \multicolumn{3}{|c|}{ Predsol (19) } & \multicolumn{3}{|c|}{ Betnesol (20) } \\
\hline & $\begin{array}{l}\text { Mean } \\
\text { score }\end{array}$ & $\begin{array}{l}\% \text { Initial } \\
\text { score }\end{array}$ & $p$ & $\begin{array}{l}\text { Mean } \\
\text { score }\end{array}$ & $\begin{array}{l}\% \text { Initial } \\
\text { score }\end{array}$ & $p$ & $\begin{array}{l}\text { Mean } \\
\text { score }\end{array}$ & $\begin{array}{l}\% \text { Initial } \\
\text { score }\end{array}$ & $p$ \\
\hline Initial & $9 \cdot 65$ & 100 & & $9 \cdot 10$ & 100 & & $7 \cdot 50$ & $10(x)$ & \\
\hline 7 Days & $7 \cdot 50$ & 78 & $<0 \cdot 03$ & 6.63 & 73 & $<0 \cdot(032$ & $4 \cdot 05$ & 54 & $<0 \cdot(001$ \\
\hline 14 Days & $6 \cdot 70$ & 69 & $<0.03$ & $5 \cdot 21$ & 57 & $<0 \cdot(011$ & $2 \cdot 70$ & 36 & $<0 \cdot(x) 1$ \\
\hline 21 Days & $6 \cdot 50$ & 67 & $<0 \cdot(1)$ & $4 \cdot 58$ & 50 & $<0 \cdot 010$ & $2 \cdot 10$ & 28 & $<0 \cdot(x) 1$ \\
\hline
\end{tabular}

in either total symptom scores at $1,3,7,14$, and 21 days or change in total symptom scores at days 3,7 , 14 , and 21.

Sign scores. Signs were assessed by the examining ophthalmologist according to the scheme shown in Table 1 at the initial visit and subsequently at $3,7,14$, and 21 days.

Because individual sign scores are weighted for severity of the sign, it is permissible to sum the scores for each patient in order to obtain an overall total sign score that represents a measure of inflammation for that patient. This is a statistical procedure used in previous trials of this sort. ${ }^{67}$ Table 4 and Fig. 1 show treatment group mean total sign scores at the initial visit and at subsequent follow-up, together with a within-group statistical analysis. Comparisons between treatment groups for either total sign scores at days $1,3,7,14$, and 21 or change from baseline total sign scores at days $3,7,14$, and 21 showed no statistically significant differences between the three groups. Nevertheless the trend shows that the greatest and most rapid response was seen in the Betnesol treated group. Predsol and tolmetin gave similar results.

Stratified formal analysis. An alternative approach to the analysis of the three groups would have been to stratify the patients into mild or severe cases based on the absence or presence of certain signs. ${ }^{6}$ It was felt that more reliance could be placed on ocular sign scores than the subjective symptom scores. Patients were classed as severe if, at their initial assessment, they had any of the following signs: ptosis, exudate, stationary aqueous, or hypopyon. ${ }^{6}$ The results of this analysis are shown in Table 5. The Predsol and Betnesol treated groups had a similar distribution of mild and severe patients, but the tolmetin group had twice as many cases in the severe category as in the mild category.

At the end of the trial patients were classified by one of us (JAD) as cured or not cured on a clinical impression basis. The results of this analysis are also shown in Table 5. Cure rates were similar for tolmetin and Predsol but better for Betnesol.

Intraocular pressure. Intraocular pressure (IOP) was measured in most patients in both the inflamed and non-inflamed eyes. IOP was often lower in the affected eye at the initial visit. In $17 \%$ of patients pressures were the same and in $25 \%$ higher than in the non-inflamed eye. The distribution was similar in all three groups. In $40-50 \%$ of the patients the pressure rose slightly during the trial and remained the same or decreased in the remainder. Only one patient showed a large rise in IOP at any time during the trial (at day three in the Predsol group), but the pressure returned to near normal by the end of the trial.

Side effects. Six out of 20 patients $(30 \%)$ in the tolmetin group commented on transient stinging of the eye with the tolmetin drops. One patient in the Predsol group complained of eye irritation with the Predsol drops, and two patients in this group complained of stinging of the eye with atropine. There were no complaints of stinging or irritation in the Betnesol group.

Table 5 Clinical judgment of treatment success or failure

\begin{tabular}{|c|c|c|c|c|c|c|}
\hline \multirow[t]{2}{*}{ Group } & \multirow{2}{*}{$\begin{array}{l}\text { Number cured } \\
\text { number at start }\end{array}$} & \multirow[t]{2}{*}{ Cured \% } & \multicolumn{2}{|c|}{ Initial assessment of cases } & \multicolumn{2}{|c|}{ Assessment of cases cured } \\
\hline & & & Mild & Severe & Mild & Severe \\
\hline Tolmetin & $12 / 21$ & 57 & 7 & 14 & 5 & 7 \\
\hline Predsol & $13 / 19$ & 68 & 8 & 11 & 3 & 10 \\
\hline Betnesol & $18 / 20$ & 90 & 10 & 10 & 9 & 9 \\
\hline
\end{tabular}




\section{Discussion}

This trial has shown that as regards patient symptoms there was little difference between the three treatment groups, which confirms previous studies ${ }^{67}$ showing that this improvement is brought about by atropine or the natural behaviour of the disease. When we compared reductions in inflammatory signs Betnesol was found to be superior to Predsol and tolmetin, but the power of the trial was such that this difference did not reach statistical significance. As shown in the stratified formal analysis it is evident that the trial was weighted against tolmetin, because that particular group had the highest number of severe cases at the outset of the trial.

As previous trials have shown,${ }^{67}$ most cases of mild uveitis would probably resolve without the use of anti-inflammatory agents, and one is therefore most concerned about the treatment of severe cases. The difficulty arises, however, when cases are initially assessed. There is no way of knowing, on clinical grounds, which cases will remain mild or moderately affected and which cases will become severe, and so all cases must be treated.

An indication of the variable course of the disease can be seen in an analysis of the cases withdrawn or failed. Of six cases failed in the Predsol group five were mild initially, and of nine cases withdrawn in the tolmetin group seven were severe initially. Of the 12 cases successfully treated in the tolmetin group seven were severe initially. If a stratified trial is to be used, then very large numbers of cases are required to be able to carry out within- and between-group analyses of sufficient power. In this trial the numbers were too low to allow any reasonable comparisons after stratification.

It would be extremely helpful if there were some factors present that might indicate whether a particular case would be severe and therefore definitely require anti-inflammatory treatment. A previous study $^{18}$ has shown a high percentage of HLA-27 positive antigen in severe cases and in patients with a previous history of uveitis, and shows its close aetiological relationship to ankylosing spondylitis and Reiter's syndrome. HLA studies, however, are expensive and not usually routinely done on uveitis cases. In the present trial there was a fairly even spread of cases with previous uveitis or clinical or radiological evidence of ankylosing spondylitis or sacroiliitis between the mild and severe groups. Therefore, there are no factors here that would indicate those cases likely to be severe.

Non-steroidal anti-inflammatory agents may not prove to be completely effective in acute endogenous non-granulomatous uveitis, because the lymphocytic infiltrations associated with this condition are probably modulated by products of arachidonic acid metabolism other than the ubiquitous prostaglandins. Further clinical trials of tolmetin in other models of inflammation such as postoperative and traumatic uveitis, where prostaglandins play a more major role in the inflammatory condition, are clearly indicated before topical tolmetin can be unequivocally recommended, but the results of this trial certainly warrant such studies.

Tolmetin will have a clinical advantage over steroidal preparations only if it can be shown that it does not have their disadvantages. Non-steroidal anti-inflammatory agents are effective in both normal and adrenalectomised animals, and widespread clinical usage has shown that adrenal suppression does not occur. Unlike the steroids there is no evidence that topical tolmetin has any adverse effect on intraocular pressure. ${ }^{1 "}$ Five known steroid responders treated with $5 \cdot 0 \%$ tolmetin three times a day for six weeks showed no ocular pressure rise (R Mapstone, personal communication). In a murine model of viral keratitis, in which topical steroids are known to enhance viral replication, topical tolmetin did not do so and was indistinguishable from saline in this regard (A B Tullo, personal communication).

Young et al..$^{21}$ reported that they could detect no statistically significant differences between Predsol, saline, and tolmetin in a trial similar to our own. Trials have been carried out with placebo controls and positive (steroid) controls in which differences were observed with their use in anterior uveitis, as mentioned earlier, and so it is difficult to draw conclusions from their study. We did not include a placebo control group and are therefore unable to make unequivocal statements about the true efficacy of either of the steroids we tested or of tolmetin. It is possible to say only that tolmetin was statistically indistinguishable from either Predsol or Betnesol, and that further clinical trials are indicated.

We are most grateful to all the consultants at Manchester Royal Eyc Hospital for referring their patients to us. The tolmetin cycdrops were provided by Smith and Nephew Rescarch Ltd, and this paper would not have been possible without the expert statistical analyses carricd out by Mrs K. Shawlcy. We arc also most grateful to Mrs Joyce Marlow for secretarial assistance.

\section{References}

1 Luntz MH. A clinical approach to the medical treatment of uveitis. Adv Ophthalmol 1978; 36: 187-96.

2 Knopf MM. A double blind study of fluoromethalone. Am J Ophthalmol 1970; 70: 739-40.

3 Fairbairn WD, Thorson JC. Fluoromethalonc. Anti-inflammatory and intra-ocular pressure effects. Arch Ophthalmol 1971; 86: $138-41$.

4 Corboy JM. Corticosteroid therapy for the reduction of postopcrative inflammation after cataract extraction. $\mathrm{Am} J \mathrm{Oph}$ thalmol 1978; 82: 923-7.

5 Hunter PJL, Fowler PD, Wilkinson P. Treatment of anterior 
uveitis. Comparison of oral oxyphenbutazone and topical steroids. BrJ Ophthalmol 1973; 57: 892-6.

6 Dunne JA, Travers JP. A double-blind clinical trial of topical steroids in anterior uvcitis. BrJ Ophthalmol 1979; 63: 762-7.

7 Ramsell TG, Bartholomew RS, Walker SR. Clinical evaluation of clobetasone butyratc: a comparative study of its effects on postoperative inflammation and on intraocular pressure. $\mathrm{Br} J$ Ophthalmol 1980; 64: 43-5.

8 Eilon LA, Walker SR. Clinical cvaluation of clobetasone butyrate cycdrops in the treatment of anterior uveitis and its cffect on intraocular pressurc. Br J Ophthalmol 1981; 65: 644-7.

9 Goldman H. Cortisone glaucoma. Arch Ophthalmol 1962; 68: 621.

10 Becker B, Mills DW. Corticostcroids and intra-ocular pressurc. Arch Ophthalmol 1963; 70: 500.

11 Patterson A, Jones BR. The management of ocular herpes. Trans Ophthalmol Soc UK 1967; 87: 59.

12 Whitclocke RAF, Eakins KE, Bennett A. Acute anterior uveitis and prostaglandins. Proc $R$ Soc Med 1973; 66: 429-34.

13 Podos SM. Prostaglandins, non-steroidal anti-inflammatory agents and eyc discase. Trans Am Ophthalmol Soc 1976; 74: 637-60.
14 Mishima S, Masuda K. Prostaglandins and the cyc: a revicw of clinical implications. Metab Pediatr Ophthalmol 1979; 3: 179-86.

15 Brodgen RN, Hecl RC, Spcight TM, Avery G. Tolmetin: a revicw of its pharmacological propertics and therapeutic efficacy in rheumatic diseases. Drugs 1978; 15: 429-50.

16 Taylor RJ, Salata JJ. Inhibition of prostaglandin synthetase by tolmetin (Tolectin McN-2559), a new non-steroidal anti-inflammatory agent. Biochem Pharmacol 1976; 25 : 2479-84.

17 Gilbert D. Horlington M. Effects of a topically applicd nonsteroidal anti-inflammatory drug, tolmetin, on experimentally induced uvcitis in the rabbit. Proc Int Soc Eye Res 1982; 2: 105.

18 Mapstone R, Woodrow JC. HL-A 27 and acute anterior uveitis. BrJ Ophthalmol 1975; 59: 270-5.

19 Gilbert D, Kolthammer J, Wigens A. Effects of a topically applicd non-stcroidal anti-inflammatory drug, tolmetin, on the intra-ocular pressure of normal rabbits and of human steroid responders. Proc Int Soc Eye Res 1982; 2: 107.

20 Young BJ, Cunningham WF, Akingbehin T. Double-masked controlled clinical trial of $5 \%$ tolmetin versus $0.5 \%$ predinsolone versus $0.9 \%$ saline in acute endogenous non-granulomatous anterior uveitis. Br J Ophthalmol 1982; 66: 389-91. 